\title{
Effect of etomidate on the oxidative stress response and levels of inflammatory factors from ischemia-reperfusion injury after tibial fracture surgery
}

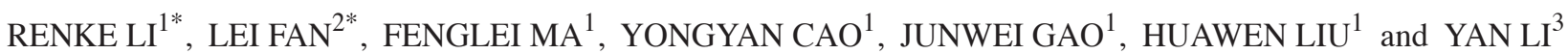 \\ ${ }^{1}$ Department of Anesthesiology, Zhengzhou Orthopaedics Hospital; ${ }^{2}$ Women and Infants Hospital of Zhengzhou; \\ ${ }^{3}$ Department of Anesthesiology, Henan Provincial Chest Hospital, Zhengzhou, Henan 450000, P.R. China
}

Received August 25, 2016; Accepted December 30, 2016

DOI: $10.3892 /$ etm.2017.4037

\begin{abstract}
The effect of etomidate on the oxidative stress response and levels of inflammatory factors resulting from ischemia-reperfusion injury of the lower extremities during tibial fracture surgery were investigated. From December 2013 to June 2015, 60 tibial fracture patients with surgical indications for open reduction and internal fixation were selected. Patients were randomly divided into the observation group and the control group. All patients were stanched by tourniquet hemostasis. Patients in the observation group were anesthetized with etomidate $(3-6 \mathrm{mg} / \mathrm{kg} \cdot \mathrm{h})+$ remifentanil (0.1-0.25 $\mu \mathrm{g} / \mathrm{kg} / \mathrm{min})$ administered with an injection pump to maintain intraoperative sedation and analgesia anesthesia. Patients in the control group received propofol $(3-6 \mathrm{mg} / \mathrm{kg} \cdot \mathrm{h})+$ remifentanil $(0.1-0.25 \mu \mathrm{g} / \mathrm{kg} / \mathrm{min})$. Before surgery (T0), before surgery was completed and anesthesia was stopped (T1), $24 \mathrm{~h}$ after surgery (T3), $48 \mathrm{~h}$ after surgery (T4), and 1 week after surgery (T5), serum superoxide dismutase (SOD) activity was determined with a kit, and ELISA was used to measure the levels of tumor necrosis factor (TNF)- $\alpha$, interleukin (IL)-1, and IL-6 in peripheral blood from both groups of patients. Surgery in both groups was completed smoothly. We found that serum SOD levels of patients in the observation group were significantly higher than those of the control group, while the levels of TNF- $\alpha$, IL-1, and IL- 6 released by neutrophils were significantly decreased after ischemia-reperfusion injury $(\mathrm{P}<0.05)$. Postoperative length of stay in hospital of the observation group was significantly shorter and the occurrence rate of
\end{abstract}

Correspondence to: Ms. Yan Li, Department of Anesthesiology, Henan Provincial Chest Hospital, 1 Weiwu Road, Zhengzhou, Henan 450000, P.R. China

E-mail: ny04vt@163.com

${ }^{*}$ Contributed equally

Key words: tibial fracture, ischemia reperfusion injury, superoxide dismutase, inflammatory factor, etomidate anesthesia complications was significantly lower than in the control group $(\mathrm{P}<0.05)$. In conclusion, during surgery for lower limb fracture, the use of etomidate for maintaining sedation can effectively maintain serum SOD activity and inhibit the release of inflammatory factors after ischemiareperfusion injury of the fracture, to reduce the occurrence rate of anesthesia complications after surgery.

\section{Introduction}

Tibial fractures account for 3-4\% of all fractures, and are one of the most common types of fractures in older people (1). With the extension of human longevity and bone loss, the incidence rate of osteoporosis and tibial fractures has increased, especially in the aging population, and has become a serious social problem (2). Open reduction and internal fixation are usually used for the treatment of tibial fractures. However, a clinical study found that using tourniquets for long periods of time caused compression hemostasis, and after the surgery was completed and the tourniquet was dismantled, patients were often accompanied by varying degrees of ischemia-reperfusion injury of the lower extremities (3). The specific postoperative manifestations included lower limb swelling, pain, numbness, minor lower limb necrosis, and soft tissue injury, which severely influenced postoperative recovery and quality of life of patients (4).

Studies found that when tourniquets were dismantled and blood supply was restored postoperatively, excessive free radicals in blood attack cells within the tissues that regained blood supply, and caused tissue damage (5). This process is known as ischemia-reperfusion injury. The ability to synthesize antioxidative enzymes in ischemic tissue that could scavenge free radicals was impaired, which aggravated tissue injury caused by free radicals after ischemia and reperfusion. Superoxide dismutase (SOD) can clear free radicals and has a protective effect against ischemia-reperfusion injury.

Ischemia-reperfusion injury of the lower extremities is often accompanied by different levels of release of inflammatory cytokines from neutrophils (6) such as interleukin (IL)-6 and TGF- $\alpha$. In addition, it can decrease SOD activity in vivo. Therefore, during anesthesia, maintaining the highest possible 
levels of SOD activity can help to reduce the release of inflammatory cytokines and inflammatory cell infiltration, and therefore represents an important method of improving the prognosis of patients (7).

Based on previous research, etomidate and propofol were applied respectively for anesthesia maintenance during surgery in the two groups of patients with tibial fracture, and the effects of the two anesthetics on inflammatory factors and SOD activity were analyzed (8).

\section{Patients and methods}

From December 2013 to June 2015, 60 patients with tibial fractures that conformed with the surgical indications of open reduction and internal fixation were selected. Patients were randomly divided into two groups, the observation group and the control group. There were no significant differences in age, body mass index (BMI), and gender ratio between the two groups $(\mathrm{P}>0.05)$ (Table I).

Inclusion criteria. The inclusion criteria were as follows: i) Patients were diagnosed with tibial fractures though clinical and imaging examinations; ii) age of patients was 18-60 years; and iii) manual reduction was invalid, or patients were accompanied by tibial structural damage and manual reduction could not be carried out.

Exclusion criteria. The exclusion criteria were as follows: i) Patients taking immunosuppressants; ii) patients with severe and/or chronic bacterial and/or viral infections; iii) patients with autoimmune diseases; iv) patients with connective tissue diseases; v) patients with malignant tumors; vi) patients with liver and kidney dysfunction; vii) patients with chronic muscle disease; viii) patients with peripheral vascular disease, chronic heart failure, thyroid disease, severe trauma that occurred half a year before the study, and a history of surgery; ix) patients with diabetes; $x$ ) patients with grade III and IV New York Heart Association classification; xi) hormone replacement therapy or other immune modulators were given to patients within the past 6 months; xii) patients and their families could not cooperate; and xiii) patients with a history of mental illness (2).

Specimen collection. Fasting venous blood $(3 \mathrm{ml})$ was collected in the early morning and placed in ordinary plastic tubes. Next, $1.8 \mathrm{ml}$ venous blood was transferred to anticoagulant tubes containing $0.2 \mathrm{ml} 3.8 \%$ sodium citrate. Specimens were centrifuged $(1,200 \mathrm{xg})$ within $1 \mathrm{~h}$ for $10 \mathrm{~min}$. Serum or plasma were separately extracted and stored in $0.5 \mathrm{ml}$ Eppendorf tubes at $-30^{\circ} \mathrm{C}$, and used within 1 month.

Measurement of serum TNF- $\alpha, I L-1$, and IL- 6 by ELISA. Before surgery (T0), before surgery was completed and anesthesia was stopped (T1), $24 \mathrm{~h}$ after surgery (T3), $48 \mathrm{~h}$ after surgery (T4), and 1 week after surgery (T5), the levels of tumor necrosis factor (TNF)- $\alpha$, IL-1, and IL-6 was measured by enzyme-linked immunosorbent assay (ELISA). All reagents in this study were from Wuhan Boster Biological Engineering Co. (Wuhan, China) and used according to the manufacturer's instructions.
Table I. Baseline parameters of patients.

\begin{tabular}{lcccc}
\hline Groups & Cases & $\begin{array}{c}\text { Age } \\
\text { (years })\end{array}$ & $\begin{array}{c}\text { BMI } \\
\left(\mathrm{kg} / \mathrm{m}^{2}\right)\end{array}$ & $\begin{array}{c}\text { Gender ratio } \\
(\text { male/female })\end{array}$ \\
\hline Observation & 30 & $52.4 \pm 4.3$ & $22.3 \pm 2.2$ & $24 / 25$ \\
Control & 30 & $49.8 \pm 11.2$ & $23.2 \pm 1.5$ & $28 / 21$ \\
T-value & - & 0.87 & 0.44 & 0.41 \\
P-value & - & 0.15 & 0.65 & 0.57 \\
\hline
\end{tabular}

BMI, body mass index.

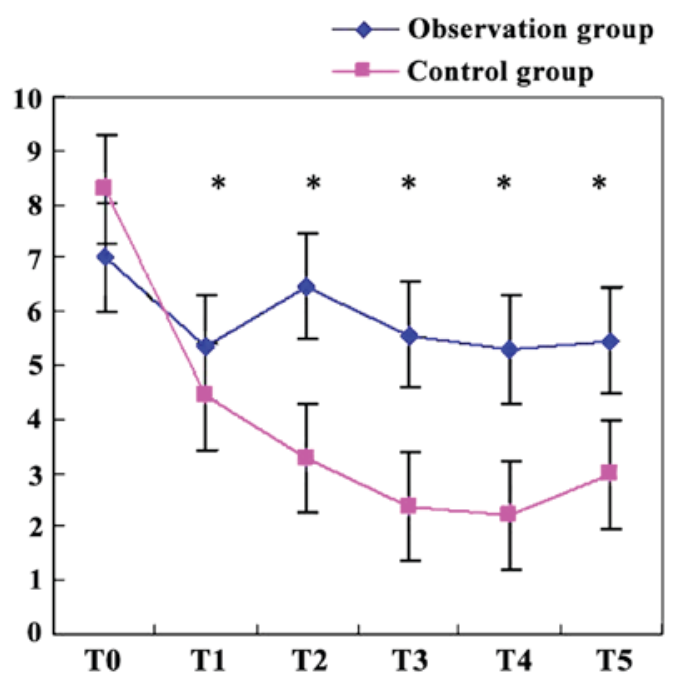

Figure 1. Beginning from T2, SOD activity in the observation group was significantly higher than in the control group $\left({ }^{*} \mathrm{P}<0.05\right)$. SOD, superoxide dismutase.

Measurement of SOD activity. Before surgery (T0), before surgery was completed and anesthesia was stopped (T1), $24 \mathrm{~h}$ after surgery (T3), $48 \mathrm{~h}$ after surgery (T4), and 1 week after surgery (T5), the measurement of serum SOD activity was performed strictly in accordance with the instructions of the SOD kit (Nanjing Institute of Biological Engineering, Nanjing, China).

Anesthesia. i) For anesthesia induction, the two groups of patients were treated with remifentanil injection $(0.2-0.3 \mu \mathrm{g} / \mathrm{kg})$, cisatracurium besilate $(500 \mu \mathrm{g} / \mathrm{kg}, \mathrm{H} 20060927$; Jiangsu Hengrui Medicine Co., Ltd., Lianyungang, China), and midazolam injection $(0.5-0.1 \mathrm{mg} / \mathrm{kg}, \mathrm{H} 19990027$; Jiangsu Enhua Pharmaceutical, Xuzhou, China). Etomidate (3 mg/kg) was used in the observation group, and propofol $(1 \mathrm{mg} / \mathrm{kg})$ was used in the control group for anesthesia induction; and ii) for intraoperative maintenance, continuous micro syringe pump infusion of propofol [3-6 $\mathrm{mg} /(\mathrm{kg} \cdot \mathrm{h})]$ and remifentanil (0.1-0.25 $\mu \mathrm{g} / \mathrm{kg} / \mathrm{min}$, remifentanil hydrochloride injection, batch no. of product, 6130314; Humanwell Pharmaceutical Co., Ltd., Yichang, China) were applied for intravenous anesthesia in the control group. Continuous micro syringe pump infusion of etomidate [3-6 mg/(kg.h); Jiangsu Enhua Pharmaceutical] and remifentanil $(0.1-0.25 \mu \mathrm{g} / \mathrm{kg} / \mathrm{min})$ were applied for intravenous anesthesia in the observation group. 
Table II. The comparison of serum SOD activity between the two groups at the six time points (mean \pm SD).

\begin{tabular}{lccccccc}
\hline Groups & Cases & T0 & T1 & T2 & T3 & T4 & T5 \\
\hline Observation & 30 & $7.02 \pm 0.75$ & $5.33 \pm 2.2$ & $6.48 \pm 1.38$ & $5.58 \pm 3.28$ & $5.29 \pm 0.48$ & $5.47 \pm 0.82$ \\
Control & 30 & $8.27 \pm 0.48$ & $4.42 \pm 1.5$ & $3.27 \pm 0.58$ & $2.37 \pm 0.48$ & $2.21 \pm 0.42$ & $2.60 \pm 0.47$ \\
T-value & - & 0.87 & 0.44 & 19.42 & 10.78 & 12.84 \\
P-value & - & 0.15 & 0.65 & 0.004 & 0.005 & 0.006 \\
\hline
\end{tabular}

SOD, superoxide dismutase.

Table III. The comparison of serum levels of TNF- $\alpha$, IL-1, and IL-6 between the two groups at the six time points (mean \pm SD).

\begin{tabular}{|c|c|c|c|c|c|c|c|c|}
\hline Title & Groups & Cases & T0 & $\mathrm{T} 1$ & $\mathrm{~T} 2$ & $\mathrm{~T} 3$ & $\mathrm{~T} 4$ & T5 \\
\hline \multirow[t]{4}{*}{$\mathrm{TNF}-\alpha(\mathrm{ng} / \mathrm{ml})$} & Observation & 30 & $12.02 \pm 0.75$ & $25.33 \pm 2.2$ & $16.48 \pm 3.8$ & $15.58 \pm 3.28$ & $15.29 \pm 4.8$ & $10.47 \pm 8.2$ \\
\hline & Control & 30 & $13.12 \pm 0.48$ & $34.42 \pm 1.5$ & $33.27 \pm 5.8$ & $22.37 \pm 0.48$ & $22.21 \pm 4.2$ & $20.60 \pm 4.7$ \\
\hline & T-value & - & 0.87 & 0.24 & 18.42 & 12.78 & 16.84 & 17.38 \\
\hline & P-value & - & 0.17 & 0.62 & 0.003 & 0.004 & 0.005 & 0.006 \\
\hline \multirow[t]{4}{*}{ IL-1 (ng/ml) } & Observation & 30 & $16.13 \pm 5.23$ & $37.4 \pm 1.26$ & $20.33 \pm 1.33$ & $10.68 \pm 2.31$ & $11.03 \pm 0.48$ & $9.81 \pm 0.38$ \\
\hline & Control & 30 & $15.21 \pm 3.28$ & $31.5 \pm 0.47$ & $19.42 \pm 1.28$ & $15.47 \pm 3.28$ & $16.32 \pm 2.31$ & $18.82 \pm 2.43$ \\
\hline & T-value & - & 0.34 & 0.67 & 12.47 & 13.23 & 14.37 & 20.38 \\
\hline & P-value & - & 0.78 & 0.38 & 0.024 & 0.021 & 0.031 & 0.002 \\
\hline \multirow[t]{4}{*}{ IL-6 (ng/ml) } & Observation & 30 & $4.33 \pm 1.23$ & $7.48 \pm 3.28$ & $4.33 \pm 2.14$ & $3.24 \pm 1.24$ & $2.14 \pm 2.76$ & $3.28 \pm 1.29$ \\
\hline & Control & 30 & $4.18 \pm 1.33$ & $8.48 \pm 1.24$ & $8.60 \pm 1.29$ & $9.03 \pm 0.48$ & $8.74 \pm 1.27$ & $7.38 \pm 2.13$ \\
\hline & T-value & - & 0.61 & 0.52 & 19.32 & 21.25 & 13.24 & 9.84 \\
\hline & P-value & - & 0.39 & 0.44 & 0.002 & 0.001 & 0.016 & 0.023 \\
\hline
\end{tabular}

TNF, tumor necrosis factor; IL, interleukin.

Table IV. The comparison of postoperative complications between the two groups of patients.

\begin{tabular}{|c|c|c|c|c|c|}
\hline Groups & Cases & $\begin{array}{l}\text { Lower } \\
\text { limb pain }\end{array}$ & $\begin{array}{l}\text { Numbness of the } \\
\text { lower limbs }\end{array}$ & $\begin{array}{l}\text { Coldness of the } \\
\text { lower limbs }\end{array}$ & Normal \\
\hline Observation & 30 & 2 & 5 & 3 & 39 \\
\hline Control & 30 & 12 & 8 & 3 & 26 \\
\hline$\chi^{2}$ value & - & \multirow{2}{*}{\multicolumn{4}{|c|}{43.78}} \\
\hline P-value & - & & & & \\
\hline
\end{tabular}

Statistical analysis. SPSS 20.0 software was used for data analysis. Data are presented as mean \pm standard deviation (SD), independent sample t-test was used for comparisons between groups, and a paired t-test was used among groups. $\mathrm{P}<0.05$ was considered statistically significant.

\section{Results}

The comparison of serum SOD activity between the two groups at six time points (mean $\pm S D$ ). The serum SOD activity between the two groups at the six time points were recorded and compared. Beginning at T3, SOD levels in the control group decreased significantly compared with the observation group $(\mathrm{P}<0.05)$ (Table II and Fig. 1).
The comparison of serum levels of TNF- $\alpha, I L-1$, and IL-6 between the two groups at six time points (mean $\pm S D)$. The comparison of the levels of TNF- $\alpha$, IL-1, and IL- 6 in serum at the six time-points indicated that, beginning from $\mathrm{T} 2$, the serum levels of TNF- $\alpha$, IL-1, and IL- 6 in the observation group decreased significantly compared with the control group $(\mathrm{P}<0.05)$ (Table III).

Comparison of postoperative complications between the two groups of patients. The postoperative complications of the two groups of patients were compared, demonstrating that the symptoms, including lower limb pain, numbness, and coldness, were significantly less in the observation compared with the control group $\left(\chi^{2}=43.78, \mathrm{P}<0.05\right)$ (Table IV). 


\section{Discussion}

Etomidate belongs to the class of nonbarbiturate intravenous sedatives, and is a form of imidazole derivative used in general anesthesia $(9,10)$. It is believed that etomidate has a better protective effect when patients with cardiovascular disease are under anesthesia for surgery. When using routine clinical doses, heart rate, mean arterial pressure, mean pulmonary arterial pressure, pulmonary capillary wedge pressure, central venous pressure, cardiac stroke volume, cardiac index, pulmonary vascular resistance, and peripheral vascular resistance between cardiac patients and normal patients had almost no differences. Etomidate exerts its pharmacological function through the $\mathrm{GABA}_{\mathrm{A}}$ receptors. The hypnotic effects of etomidate are mediated through the $\beta 2$ and $\beta 3$ subunits of $\mathrm{GABA}_{\mathrm{A}}$ receptors rather than the $\alpha 1$ subunit, and $\mathrm{GABA}_{\mathrm{A}}$ receptor antagonists can antagonize the effects $(11,12)$. In our study, serum SOD activity and the levels of inflammatory factors of the two groups at six time points were compared. Compared with the control group, the levels of serum SOD and TNF- $\alpha$, IL-1, and IL-6 released by neutrophils after ischemia-reperfusion injury in the observation group (treated with etomidate) were significantly decreased $(\mathrm{P}<0.05)$. These results were similar to a previous study, which showed that in ischemia-reperfusion injury, because of ischemia, the levels of IL-10 and TNF- $\alpha$ increased, which can increase T lymphocyte infiltration (13). SOD activity was also an important factor. SOD is an active substance derived from cells, that can eliminate harmful substances produced during metabolic processes, and has an anti-aging effect. After tibial fracture, because of ischemia and hypoxia, a large amount of oxygenfree radical are generated in local tissue and in circulation. SOD is a primary substance that scavenges reactive oxygen species (ROS) (14). We found that ROS levels increased significantly in patients with tibial fracture, which may be related to ischemia-reperfusion injury after using tourniquets for a long period of time.

$\mathrm{Yu}$ et al found that etomidate had a protective effect on ischemia-reperfusion injury of the spinal cord induced by interruption of the rabbit aorta (15). Ergün et al found that anesthetic doses of propofol, ketamine, and etomidate had protective effects on ischemia-reperfusion injury of skeletal muscle, and there were no obvious differences between them (16). However, Harman et al employed an intrauterine model of hypoxia of fetal rats, simulated by clamping the ovarian uterine artery of pregnant rats, and etomidate, midazolam, propofol and other commonly used anesthetic drugs were used during the intervention. The results indicated that only propofol and midazolam had neuroprotective effects, and significant neuroprotective roles of other narcotic drugs were not observed (17). Yuzer et al showed that propofol and thiopental can significantly reduce ischemia-reperfusion injury of the kidney. The protective effects of these drugs may be attributed to the antioxidant functions of narcotic drugs. Their results showed that anesthesia with propofol and thiopental had good effects on improving renal function (18). We believe the controversy surrounding these findings may be attributed to surgical approaches, injury of organs, and ischemia-reperfusion injury, although further animal studies are required for validation.
We observed that the postoperative length of stay in hospital of patients in the observation group was significantly shorter than that of the control group, and the occurrence rate of anesthesia complications was significantly decreased $(\mathrm{P}<0.05)$. We hypothesized that inflammatory cytokines are released from ischemia-reperfusion injury of the lower limbs and that the levels of ROS in the body affect the functions of the lower extremities. While etomidate had a good effect on reducing the levels of ROS and the release of inflammatory factors (16-23), the specific mechanisms still need to be explored by in vivo and in vitro experiments.

In conclusion, tourniquets are routinely applied for hemostasis during surgery for open tibial fractures. The intraoperative use of etomidate for maintaining sedation can effectively decrease serum SOD levels and the release of inflammatory factors after ischemia-reperfusion injury. In addition, it can effectively decrease the occurrence rate of complications from anesthesia after surgery.

\section{References}

1. Court-Brown CM and McBirnie J: The epidemiology of tibial fractures. J Bone Joint Surg Br 77: 417-421, 1995.

2. Ludwig M, Hymes RA, Schulman J, Pitta M and Ramsey L: intramedullary nailing of open tibial fractures: provisional plate fixation. Orthopedics 30: 1-6, 2016.

3. Brink O: Suprapatellar nailing of tibial fractures: surgical hints. Curr Orthop Pract 27: 107-112, 2016.

4. Fu B: Locked META intramedullary nailing fixation for tibial fractures via a suprapatellar approach. Indian J Orthop 50: 283-289, 2016

5. Chopineau J, Sommier MF and Sautou V: Evaluation of free radical production in an ischaemia-reperfusion model in the rabbit using a tourniquet. J Pharm Pharmacol 46: 519-520, 1994.

6. Dai Y, Jia P, Fang Y, Liu H, Jiao X, He JC and Ding X: miR-146a is essential for lipopolysaccharide (LPS)-induced cross-tolerance against kidney ischemia/reperfusion injury in mice. Sci Rep 6: 27091, 2016.

7. Han JQ, Liu CL, Wang ZY, Liu L, Cheng L and Fan YD: Anti-inflammatory properties of lipoxin A4 protect against diabetes mellitus complicated by focal cerebral ischemia/reperfusion injury. Neural Regen Res 11: 636-640, 2016.

8. Zhou X: Effects of etomidate or propofol on inflammation mediators in rabbit with spinal injury. Chin J Pract Nervous Dis $13,2010$.

9. Sedighinejad A, Naderi Nabi B, Haghighi M, Biazar G, Imantalab V, Rimaz S and Zaridoost Z: Comparison of the effects of low-dose midazolam, magnesium sulfate, remifentanil and low-dose etomidate on prevention of etomidate-induced myoclonus in orthopedic surgeries. Anesth Pain Med 6: e35333, 2016.

10. Wang L, Li W, Xu R and Long L: Meta analysis for the anesthesia effect and adverse reactions of etomidate and propofol on the painless abortion surgery. Zhong Nan Da Xue Xue Bao Yi Xue Ban 41: 427-433, 2016 (In Chinese).

11. Allen $\mathrm{C}$ and Washington $\mathrm{S}$ : The role of etomidate as an anaesthetic induction agent for critically ill patients. Br J Hosp Med (Lond) 77: 282-286, 2016.

12. Yılmaz Çakirgöz M, Demirel İ, Duran E, Özer AB, Hancı V, Türkmen ÜA, Aydın A, Ersoy A and Büyükyıldırım A: Effect of gabapentin pretreatment on myoclonus after etomidate: a randomized, double-blind, placebo-controlled study. Rev Bras Anestesiol 66: 356-362, 2016.

13. Patil CN, Wallace K, LaMarca BD, Moulana M, Lopez-Ruiz A, Soljancic A, Juncos LA, Grande JP and Reckelhoff JF: Low-dose testosterone protects against renal ischemiareperfusion injury by increasing renal IL-10-to-TNF- $\alpha$ ratio and attenuating T-cell infiltration. Am J Physiol Renal Physiol 311: F395-F403, 2016.

14. Jiang W, Bian Y, Wang Z and Chang TM: Hepatoprotective effects of Poly-[hemoglobin-superoxide dismutase-catalase-carbonic anhydrase] on alcohol-damaged primary rat hepatocyte culture in vitro. Artif Cells Nanomed Biotechnol 5: 1-5, 2016. 
15. Yu Q, Zhou Q, Huang H, Wang Y, Tian S and Duan D: Protective effect of etomidate on spinal cord ischemia-reperfusion injury induced by aortic occlusion in rabbits. Ann Vasc Surg 24: 225-232, 2010

16. Ergün Y, Darendeli S, Imrek S, Kilinç M and Oksüz H: The comparison of the effects of anesthetic doses of ketamine, propofol, and etomidate on ischemia-reperfusion injury in skeletal muscle. Fundam Clin Pharmacol 24: 215-222, 2010.

17. Harman F, Hasturk AE, Yaman M, Arca T, Kilinc K, Sargon MF and Kaptanoglu E: Neuroprotective effects of propofol, thiopental, etomidate, and midazolam in fetal rat brain in ischemia-reperfusion model. Childs Nerv Syst 28: 1055-1062, 2012.

18. Yuzer H, Yuzbasioglu MF, Ciralik H, Kurutas EB, Ozkan OV, Bulbuloglu E, Atli Y, Erdogan O and Kale IT: Effects of intravenous anesthetics on renal ischemia/reperfusion injury. Ren Fail 31: 290-296, 2009.

19. Tvrdá E, Tušimová E, Kováčik A, Paál D, Libová L’ and Lukáč N: Protective effects of quercetin on selected oxidative biomarkers in bovine spermatozoa subjected to ferrous ascorbate. Reprod Domest Anim 51: 524-537, 2016.
20. Zhou X, Xu Y, Xie Z, Xu S and Bi J: Association of extracellular superoxide dismutase gene methylation with cerebral infarction. Zhonghua Yi Xue Yi Chuan Xue Za Zhi 33: 378-382, 2016 (In Chinese).

21. Álvarez-Zaldiernas C, Lu J, Zheng Y, Yang H, Blasi J, Solsona $\mathrm{C}$ and Holmgren A: Cellular redox systems impact the aggregation of $\mathrm{Cu}, \mathrm{Zn}$ Superoxide dismutase linked to familial amyotrophic lateral sclerosis. J Biol Chem 291: 17197-17208, 2016.

22. Bhasker TV, Gowda NK, Mondal S, Krishnamoorthy P, Pal DT, Mor A, Bhat SK and Pattanaik AK: Boron influences immune and antioxidant responses by modulating hepatic superoxide dismutase activity under calcium deficit abiotic stress in Wistar rats. J Trace Elem Med Biol 36: 73-79, 2016.

23. Zhao Y, Zhao E, Zhang C and Zhang H: Study of the changes of acrosomal enzyme, nitric oxide synthase, and superoxide dismutase of infertile patients with positive antisperm antibody in seminal plasma. Cell Biochem Biophys 73: 639-642, 2015. 